\title{
Geração sem rumo
}

Discurso pronunciado pelo orador da turma na solemnidade de collação de grau aos bacharelandos de 193I, na Faculdade de Direito de São Paulo

\section{CENTENARIO}

Precisamente ha 100 annos, iniciava o mosteiro franciscano a sua fecunda missão educativa, entregando á sociedade os seis primeiros bachareis do Brasil.

Era a parcella inicial da gloriosa galeria de seus filhos, que ingressava no scenario social de nossa terra, num momento em que facciosismos desvairados, escarnecendo da autoridade desfallecida e inerme, implantavam uma anarchia disseminada e profunda.

A gravidade desse instante sombrio, em que a angustia da nação sobresaltada appellava para as ultimas energias moraes do povo, sobrecarregava as responsabilidades das gerações emergentes, cujo valor, entretanto, soube dar galhardo desempenho ao seu papel historico, conjurando 
a desordem e escrevendo as paginas mais luminosas da vida nacional.

Por uma constatada coincidencia historica, a turma que deixa a Academia neste instante centenario, - encontra a sua patria em identico periodo politico, intercalado, como o da Regencia, no curso de sua evolução normal, em analoga atmosphera de instabilidade e inquietação, cujas difficuldades, entretanto, superam extraordinariamente as do seculo anterior, porque reflectem as incertezas de um espirito universal.

E o que faremos diante disso tudo, é a interrogação angustiada que o presente formula á

\section{NOSSA GERAÇÃ̃}

conferindo-lhe immensas e indeclinaveis responsabilidades.

A nova geração é, sem duvida, uma geração nova.

Mocidade cujo alvorecer encontra a civilisação immersa num periodo crepuscular da historia; geração cujo ingresso activo na vida social encontra a sua patria e o mundo debatendo-se no desfecho de todas as crises, traria fatalmente uma feição diversa das que a precederam.

A' mentalidade sonhadora, responsavel pelos nossos maiores prejuizos sociaes e politicos, e ao espirito desalentado que por algum tempo anniquilou a nossa mocidade, succede um pensamento novo, que vivendo o instante em que todas as questões se dramatisam, e contando com a experiencia que a gerações anteriores não foi facultada, substitue o romantismo perigoso ou a indifferença decadente, por uma visão mais realista da vida e uma vontade promissora de agir.

Falta-nos, porém, a directriz. Existe a vontade, mas não existe o pensamento orientador. Somos uma geração a quem a necessidade de vida imprimiu a ansia do combate, mas a ruina das illusões arrancou o idealismo constructivo. Falta-nos a bandeira, embora não nos falte a força. 
Estamos num desses momentos em que as consciencias abaladas ficam á espera das correntes doutrinarias, as intelligencias fluctuantes á mercê das idéas salvadoras, e os institutos educativos assumem um papel extraordinario, pela necessidade de sua acção directriz e pela facilidade de sua cathechisação ideologica.

Foi esta acção, entretanto, que o regimen de ensino vigente impediu que pudesse ser realisada durante $o$

\section{NOSSO CURSO ACADEMICO}

O estudo, quasi restricto a materias que interessam ás bancas dos futuros advogados, sem o devido apreço ás disciplinas sociaes e politicas, indifferente á orientação espiritual da mocidade, - condiciona-se a um criterio exclusivamente individualista, que rouba de nossa geração a potencialidade de um pensamento commum, dispersando-a em largas divergencias pessoaes, tendencias collidentes e individualismos improductivos.

Aggravando os effeitos desta acanhada finalidade pedagogica, - a liberdade illimitada da cathedra entrega o ensino ao sabor das mais desencontradas orientações doutrinarias dos mestres, contribuindo paulatinamente para a nossa desorganisação mental. Os ensinamentos obtidos, filiados ás mais diversas directrizes philosophicas, degladiam-se no recesso dos subconscientes, gerando conflictos surdos de principios inconciliaveis, que abalam as raizes do nosso pensamento, fazem vacillar a firmeza das nossas conclusões e enfraquecem os impulsos dos nossos idealismos.

A esta dissociação produzida pelo regimen de ensino, accrescem ainda as consequencias da organisação interna desta Casa, onde corpo docente e discente, impossibilitando a formação do almejado espirito universitario, separam-se no mais profundo desconhecimento reciproco.

Hoje, que as classes se unem em attitudes inadiaveis de defesa, e os laços de crescente solidariedade levantam con- 
tra as instituições conservadoras o desvario das incultas massas proletarias, a burguezia ainda continúa indifferente, na rivalidade de suas competições internas, subdividida, fragmentada, desarticulada. $\mathrm{E}$ nós, que constituimos elevada expressão da classe conservadora, futuros mentores das instituições combalidas, fraccionamo-nos na indecisão, no individualismo, na descrença nas forças collectivas, dispersando energias inestimaveis.

E' por isso que a esta Casa cabe, neste instante, uma responsabilidade social incalculavel. Mas para que ella a cumpra, impõe-se a implantação definitiva do regimen universitario, a eliminação do feitio individualista do nosso ensino, a subordinação de seus ensinamentos a uma directriz unificada, - emfim todo apparelhamento capaz de permittir a efficacia de sua missão social, para que se não perca inutilmente a boa vontade dos seus mestres, e o antigo esplendor de suas tradições se restaure nas glorias das gerações vindouras.

A consciencia dessa responsabilidade se amplia, se corrermos os olhos pelas occorrencias que o panorama mundial ostenta, e que

\section{O DIREITO}

espelha em todos os seus sectores.

O materialismo desabrido estende o seu dominio tentacular á propria seára da sciencia. Creando um ambiente febricitante e esmagador, onde os interesses tumultuarios dos individuos impossibilitam a meditação dos gabinetes, faz decrescer os estudos desinteressados e converte a sciencia num instrumento do egoismo, arrancando-lhe a singeleza das grandes Verdades, para vestil-a com as apparencias espectaculares e falsas das originalidades cabotinas. Surgem então as theorias extravagantes dos doutrinadores in. sinceros, que fazem da sciencia o palco para suas exhibições interessadas. 
No Direito Publico, principalmente, é que o materialismo melhor se póde constatar, emboscado nas mil e uma difficuldades que a vida systematisa nos seus problemas politicos, economicos e sociaes.

No aspecto politico, o mundo apresenta a substituição do estado liberal-democratico por um espirito mais realista, tentando reagir contra a mentalidade visionaria que nos levou a este fracasso de civilisação, pela imprevisão e extremismo de suas concepções.

O liberalismo politico, conferindo ao individuo todas as liberdades imaginarias, entregava-o á posse exclusiva de si mesmo, confessando-se, pois, um regimen delicado, que, mais do que qualquer outro, necessitaria da sombra tutelar do espiritualismo, porque era na consciencia indvidual liberta, que repousariam os destinos da sociedade politica.

Entretanto, numa inconsciencia que lhe seria fatal, no delirio de suas conquistas, impedia, elle proprio, o surto desse espiritualismo salvador, estabelecendo ao lado da igualdade civil e politica, um campo inteiramente livre para todas as desigualdades possiveis: a economia.

Era o golpe mortal no espiritualismo, pois deslocava para o sector material o interesse do homem, que só via na economia a possibilidade de progresso, eis que nas outras fórmas de aperfeiçoamento, as suas ambições esbarravam na igualdade obrigatoria da lei.

Numa involução que assignala o seu declinio, o liberalismo, que procurava livrar o homem do captiveiro social e politico, entregava-o á escravisação de si mesmo, a peor de todas as escravidões, quando a personalidade humana está entregue aos impulsos do egoismo e aos desatinos do instincto.

E como consequencias fataes desse rumo, agigantam-se ameaçadoramente os dois problemas maximos, cujas difficuldades accionam as transformações politicas da actualidade: o problema economico, e seu corollario, a questão social. 
Emquanto o liberalismo extremado delirava no extase das suas concessões, as forças materiaes que elle estimulára, começavam a agir serenamente. Emquanto o verbalismo dos doutrinadores e politicos apregoava liberdades demagogicas, LENINE doutrinava argutamente aos seus adeptos: " $E$ ' nosso dever directo desenvolver e sustentar, com a participação activa dos operarios, todo protesto liberal-democratico". (1)

E' a mesma advertencia que o livro mais novo da sociologia nacional faz ao somnambulismo politico que persiste em desconhecer a realidade: "O estado liberal cruza os braços e recita angelicamente a ode á liberdade de pensamento e de acção. Descruzando os braços diante da occasião, os communistas preparam tranquillamente a dictadura, que não dará liberdade nem de pensamento, nem de acção" (2)

E' o suicidio do estado liberal, que morre pelas proprias mãos, victima do materialismo que agasalhou irreflectidamente, e que o assalta com violencia, ameaçando levar comsigo as mais solidas e admiraveis instituições da vida.

Hoje, nesta phase ainda obscurecida pela poeira das construcções ruidas, novas correntes politicas emergem, e velhos conceitos se retemperam, ameaçados pelas incertezas do momento historico.

Se nos aventurassemos a catalogar as tendencias existentes, percrutariamos talvez, no fundo destas caudaes que revolvem o pensamento politico da humanidade, tres lemmas que synthetisam as tres fórmas estatistas do direito publico actual: liberdade, igualdade, ordem.

"Ordem" - a finalidade maxima do fascismo, cuja expressão politica talvez não passe de um gesto de legitima

(1) “O Jornal", 6-8-31, Segunda Republica, de Tristão DE Athayde.

(2) Machiavel e o Brasil, de Octavio de Faria, pag. 164. 
defesa de uma civilisação ameaçada. Pois sobrepor á igualdade e á liberdade a preoccupação exclusiva da ordem, seria inscrever como finalidade do Estado o que é apenas um meio para a consecução de seus fins.

"Igualdade" - a miragem da aspiração communista. Mas como todas as ideologias collidentes com a vida, o seu fulgar ha de ser ephemero, porquanto condicionar o homem a esse mytho politico, seria escravisal-o a um artificio que a sua natureza repelle, na expansão irreprimivel de todas as desigualdades originarias, - de ordem physica, espiritual, moral.

Resta o ideal que a democracia symbolisa. Desprest:giada embora pelos seus cultores, que levando-a ao extremismo dissolvente, reduziram-na á inanidade, subsiste ainda o ideal de "liberdade", como a expressão mais viva das tendencias naturaes do homem.

Desacreditou-o a utopia do democratismo extremádo, o qual, esquecido de que o "unico meio de garantir a liberdade é limital-a", - chegou a todas as liberdades legaes, morrendo dentro de todias as escravidões reaes.

Mas, depurada por esta crise, despida de suas illusões fataes, mais modesta em suas concessões, porém, mais fecunda em suas manifestações praticas, procurando ser antes possivel do que perfeita, - a liberdade talvez ainda se restaure, como a formula politica que mais se emquadra dentro das condições reaes da vida humana.

O direito privado tambem não foge a esse materialismo dominante.

Não ha duvida que as codificações modernas quebram o absolutismo dos principios numa reacção anti-individualista, que traz, por exemplo, á propriedade uma feição mais li- 
mitada e humana, á theoria contractual normas protectoras dos mais fracos, ao direito de familia uma acção emancipadora da mulher e tutelar dos filhos.

Mas essa transformação, longe de exprimir uma tendencia moralista, não passa de um necuo estrategico do proprio utilitarismo, ante a investida defensiva das classes syndicalisadas. $O$ direito perde o seu finalismo superior e amesquinha-se nas imposições das classes, que disputam as suas regalias ao sabor de suas ambições, reduzindo-o, no campo positivo, a uma quasi collectanea de concessões e favores.

Ainda mais. Além de não ser ditada por qualquer inspiração moral, essa tendencia protectora do individuo visa exclusivamente a melhoria de suas condições materiaes, desprezando inteiramente os direitos naturaes de sua personalidade moral: ahi está, por exemplo, a legislação de familia, reducto do direito onde a personalidade humana ainda podia encontrar refugio para suas tendencias espirituaes, progressivamente avassalada á materialidade dos contractos.

No fundo é, pois, o proprio materialismo que acciona a essa reacção anti-individualista, na tentativa inutil de se esquivar de consequencias que lhe são inevitaveis.

E' ainda o materialismo que, isolando o direito num circulo de interesses, desliga-o completamente da moral, arrancando-lhe a força subjectiva que o immunisa contra o arremesso das paixões.

E o resultado dessa inconsciencia é a fraqueza crescente de suas imposições, que se debilitam até a inanidade com que assistem, no fastigio da civilisação materialista, ao applauso do crime na glorificação de Al CaPone, diante da inefficacia policial do direito, inteiramente anniquilado pelo desamparo irreparavel da moral.

\section{CONCLUSÃO}

Desfeitas todas as tradições moraes, rompidos todos os freios espirituaes, a civilisação contemporanea attinge a um 
estagio em que a assaltam todas as difficuldades oriundas da directriz que a gerou.

O materialismo robusto, que o fetichismo das legislações abrigou no delirio dos romantismos libertarios, attinge ás fibras estructuraes da nossa civilisação, ulcerando os elementos mais fecundos do seu aperfeiçoamento social. O progresso, limitado a uma febre de crescimentos materiaes, reduz a moral a simples exigencia mundana, parcialmente applicavel em attenção ás conveniencias sociaes, - gerando essa sociedade anarchisada e decadente, cheia de opulencias e de miserias, de clamores e de inconsciencias, de classes que luctam, de problemas que ameaçam, de divergencias que desaggregam.

Determinando o anthropocentrismo denunciado pela sociologia contemporanea, nem ao menos cuida do homem na totalidade do seu ser, porquanto, a cegueira da sua visão restringe os seus desvelos á parte animal da creatura, attendendo apenas ás suas necessidades materiaes e solicitações egoistas.

E o seu espirito, a sua moral, a parte do seu ser que o eleva e dignifica, perde-se no tumulto febril das competições materiaes, esquecida e relegada como um luxo desprezivel.

E' por isso que, tentar nesolver as questões politicas, sociaes, economicas, com a therapeutica exclusiva das legislações, é remediar pela rama, corrigindo manifestações externas que surgirão continuamente, emquanto perdurar a raiz que as alimenta. As soluções isoladas - leis, decretos, regimens - são simples formulas momentaneas de applicação problematica, verdadeiras transacções ephemeras da sociedade com os males que a salteiam.

Porque emquanto o egoismo dominar o sentimento collectivo e a materia esmagar o espirito, a civilisação continuará, - na dolorosa illusão de suas sumptuosidades materiaes, - a angustiar o individuo com o peso de todas as injustiças e a tortura de todos os males. 
E a solução radical e basica está numa attitude unica e insubstituivel: a resurreição do espiritualismo.

\section{O BRASIL}

Através de tres mentalidades diversas se distribue o pensamento politico nacional.

A primeira, de precedencia historica e supremacia numerica, consubstancia o idealismo utopico que imputava aos governos a responsabilidade exclusiva das nossas difficuldades, porque entendia que não lhes poderia dar causa "a terra mais rica do universo", como proclamava o nacionalismo dos compendios, ou a "constituição mais avançada do mundo" como constatava o orgulho pueril dos nossos legisladores. A sua finalidade superficial, limitada á "mudança dos governos", expõe ao paiz a sua experiencia, através da convulsão politica que realisou violentamente os seus objectivos.

Ao lado deste espirito, entretanto, surgiu desde logo uma corrente ideologica de maior visão, responsabilisando pelos nossos males a utopia dos que queriam implantar um regimen de civilisações millenarias num povo nascente e inculto, com problemas especificos, indole propria, difficuldades diversas. A vaga aspiração revisionista concretisa-se em Silveira Martins, agasalha-se no civilismo e transformase numa verdadeira orientação politica, na obra monumental de Alberto Torres, cujo pensamento lastreou pronunciada corrente de opinião nas nossas elites.

Encarando de frente a nossa vida, verificando que a Republica vinha sendo "um jogo floral de theorias sobre um campo de miserrimas realidades", (3) esta corrente implantava na sociologia brasileira um pensamento realista e novo, que oppunha ao exotismo dos principios o nacionalismo das circumstancias e ás magnificencias juridicas da Constituição, as miserias deploraveis da nossa patria.

(3) O Problema Nacional Brasileiro, de Alberto TonRes, pag. 11. 
Sua finalidade, entretanto, ainda não satisfazia inteiramente, porquanto se limitava ao problema da organisação politica.

Dahi o surto contemporaneo de um pensamento complementar, que suppre as insufficiencias das outras soluções, avançando a sua therapeutica ao elemento vital da sociedade: o homem.

E' a terceira phase do nosso pensamento politico, cuja evolução se processa da superficie para o amago, da materia para o espirito: do idealismo utopico que se restringia á "mudança dos governos", passamos ao realismo social que almejava a "reforma do regimen" e chegamos finalmente á solução que se enquadra na renovação espiritualista da humanidade, e que, obediente ao principio da nacionalisação dos idealismos (4) implanta as suas raizes nas tradições sociaes, politicas e moraes que o materialismo imperante seccionára de nossa vida.

"As nacionalidades sadias, como os homens fortes, vivem tambem do passado, mas não vivem só no passado." Esta phrase, de um dos lideres do pensamento novo (5), define o valor das tradições, cuja acção, longe de entorpecer a actividade dos povos, vivifica os seus commettimentos com os impulsos da historia.

Essa renovação basica não é uma utopia como tantas outras, que fracassam na incomprehensão do meio. O proprio Keyserling, expoente mundial da philosophia espiritualista, expondo conclusões a que chegára, affirmou que "a America latina estava se preparando para succeder á America ingleza, em uma nova phase de civilisação, a qual, ao contrario da feição pragmatista norte-americana, se cara-

(4) O Idealismo da Constituição, de Oliveira Vianna, pag. 131.

(5) Esboço de uma introducção á Economia Moderna, de TrusTÃo de Athayde, pag. 14. 
cterisaria pela "predominancia absoluta dos valores espirituaes sobre os valores economicos". (6)

E o Brasil, como constata a nossa historia e conclue um estudioso das nossas coisas - tem um accentuado pendor espiritualista. O proprio positivismo, como exemplifica Tasso da Silveira, concretisação de tendencias materialistas, não poude dominar em nossa terra sem revestir os seus principios na atmosphera espiritual que o elevou a quasi religião.

O espiritualismo portanto, mais do que um meio favoravel, encontra em nossa patria o appello caloroso da realidade, exigindo dos nossos costumes e das nossas leis a salvaguarda das suas tendencias e o respeito sagrado ás suas inclinações profundas.

E' chegada a hora da partida.

As palavras se retráem no momento em que a commoção se alteia.

A alegria inédita deste instante em que transpomos os humbraes do templo venerando, tolda-se na lembrança de dois companheiros mortos e refreia-se na sensação dolorosa da despedida.

Os mestres desta casa, que durante cinco annos aprendemos a estimar, pela dedicação e amizade com que sempre nos honraram, e a quem devotamos sincero reconhecimento, trazem-nos a este limiar da vida profissional, volvendo novamente á sua benemerita faina educativa. Mas conforta-nos o facto de que esta separação não representa mais do que a perda de suas aulas, porquanto as suas palavras, os

(6) “O Jornal", 1-3-931, Barbaros e Civilisados, de Tristão DE ATHAYDE. 
seus ensinamentos, os seus exemplos, - esses ficarão eternamente comnosco, illuminando as nossas consciencias nos transes sombrios da existencia.

Aos collegas que ficam, companheiros que participaram das lutas e alegrias da nossa vida academica, - um grande abraço.

E ao Dr. Vicente Ráo, essa individualidade moça que tivemos a felicidade de encontrar nos primeiros passos do curso juridico, - a gratidão imperecivel de sua primeira turma, em cujos corações se eleva a admiração profunda, que o fulgor de suas aulas e a dedicação de sua amizade souberam infundir em cada um de nós.

Talento de escól, jurista eminente, mestre admiravel e amigo sincero, essa figura destacada que eregimos como paradigma do nosso pensamento irá nos entregar neste instante, através de suas palavras magistraes, os ultimos conselhos com que partiremos para a lucta.

Ouçamo-lo, pois, attentamente, para que possamos lá fóra, no torvelinho da vida pratica, prestar a esta Casa o preito de gratidão que ella merece, no culto desvelado de suas tradições, na pratica intransigente dos seus ensinamentos, defendendo o Direito e respeitando a Justiça!

CARLOS ALBERTO ALVES DE CARVALHO PINTO 